\title{
PENGARUH LATIHAN PLYOMETRIC TERHADAP HASIL SMASH PADA EKSTRAKURIKULER BOLAVOLI
}

\author{
Kurniawan $^{1}$ Gilang Ramadan ${ }^{2}$ \\ STKIP Muhammadiyah Kuningan \\ email: gilangramadan89.umku@gmail.com
}

\begin{abstract}
Abstrak
Penelitian ini di latarbelakangi oleh permasalah kemampuan pada atlet atau siswa ekstrakurikuler bolavoli putra di SMA Negeri 1 Luragung mempunyai kemampuan tolakan pada teknik dasar smash bolavoli masih rendah. Padahal untuk mencapai sebuah pukulan yang maksimal sehingga pukulan dapat di arahkan ke sasaran lapangan lawan itu bisa terarah, maka teknik dasar smash bolavoli dibutuhkan kemampuan tolakan yang tinggi. Tujuan penelitian ini untuk mengetahui pengaruh latihan plyometric terhadap hasil smash pada ekstrakurikuler bolavoli putra di SMA Negeri 1 Luragung. Metode penelitian ini adalah metode kuantitatif dengan eksperimen, pre eksperimental menggunakan desaign penelitian grup design pre test-post test.Populasi dalam penelitian ini siswa ekstrakurikuler bolavoli putra di SMA Negeri 1 Luragung 17, teknik sampel yang diterapkan dalam penelitian ini total sampeling yang artinya populasi dijadikan sampel yaitu sebanyak 17. Instrumen yang digunakan dalam penelitian tes smash, sebelum dilakukan tes siswa diberikan treatment atau Latihan Plyometric, tujuan latihan ini dilakukan dengan sengaja untuk meningkatkan kemampuan atlet yang di berikan oleh pelatih, yang merupakan perpaduan latihan kecepatan dan kekuatan. Perpaduan antara kecepatan dan kekuatan merupakan perwujudan dari daya ledak otot mekanisme latihanya yaitu meloncati paralon dan melakukan smash dan di kombinasikan dengan latihan abc runing. Terdapat pengaruh latihan plyometric terhadap hasil smash dalam permainan bolavoli pada ekstrakurikuler bolavoli putra di SMA Negeri 1 Luragung, hal ini di buktikan dari hasil statistik uji t Dari perhitungan kedua data pre test dan post test yang di dapat $t_{\text {hitung }}$ 3,89 dan dengan $n 17$ dan taraf nyata 0,05, dari daftar tabel yang di lampirkan di dapat $t_{\text {tabel }}$ 2,11. Jika dibandingkan, dapat dilihat nilai $t_{\text {hitung }}(3,89>2,11) t_{\text {tabel }}$ maka $H_{O}$ ditolak. Dengan ditolaknya $H_{O}$ disimpulkan bahwa terdapat pengaruh latihan plyometric terhadap hasil smash pada ekstrakurikuler bolavoli putra di SMA Negeri 1 Luragung.
\end{abstract}

Kata Kunci: Latihan, Plyometric, Bolavoli, Smash.

\begin{abstract}
This research was based on the background of the problem of the ability of male volleyball extracurricular athletes or students in Luragung 1 Public High School to have a low repulsion ability on the basic technique of smash volleyball. In fact, to achieve a maximum blow so that the blow can be directed at the opponent's target field can be directed, then the basic technique of smash volleyball requires a high repulsion ability. The purpose of this study was to determine the effect of plyometric training on smash results on male volleyball extracurricular activities at Luragung 1 Public High School. The method of this research is quantitative method with experimental, pre experimental using desaign research group design pre-post test. Population in this study male volleyball extracurricular students in 17 Luragung Public High School 17,
\end{abstract}


the sample technique applied in this study is total sampling which means population is made the sample is 17. Instruments used in the smash test, before the test is done the student is given a treatment or Plyometric Exercise, the purpose of this exercise is done intentionally to improve the ability of the athlete given by the coach, which is a combination of speed and strength training. The combination of speed and strength is the embodiment of the muscle explosive power of the training mechanism, which is jumping paralon and doing a smash and combined with abc runing exercises. There is the effect of plyometric training on smash results in volleyball games on male volleyball extracurricular activities at Luragung 1 Public High School, this is evidenced from the results of t test statistics. From the second calculation the pre test and post test data obtained t count 3.89 and with $n 17$ and a significant level of 0.05, from the list of tables attached to t table 2.11. When compared, it can be seen the value of $t$ count (3.89> 2.11) t table so $\mathrm{HO}$ is rejected. By rejecting $\mathrm{HO}$, it was concluded that there was an effect of plyometric training on the smash results of male volleyball extracurricular activities at Luragung 1 Public High School.

Keywords: Exercise, Plyometric, Bolavoli, Smash

\section{PENDAHULUAN}

Olahraga sebagai aktivitas fisik atau jasmani dapat memberikan kepuasankepada pelakunya sebagai kebutuhan individu. Begitu besar peran olahragaterhadap kehidupan manusia, sehinga olahraga dapat dijadikan sebagai saranauntuk sarana pendidikan olahraga dan kesehatan olahraga, rekreasi, prestasi bahkan sebagai suatu kebudayan. Pendidikan olahraga dan kesehatan pada hakikatnya adalah proses pendidikan yang memanfaatkan aktifitas fisik dan kesehatan untuk menghasilkian perubahan holistik dalam kualitas individu, baik dalam hal fisik, mental, serta emosional. Pendidikan jasmani memperlakukan anak sebagai sebuah kesatuan utuh, makhluk total, dari pada hanya menganggapnya sebagai seorang yang terpisah kualitas fisik dan mentalnya.

Permainan bolavoli adalahPermaina pada awal ide dasarnya adalah permainan memantul-mantulkan bola (to volly) oleh tangan atau lengan dari dua regu yang bermain di atas lapangan yang mempunyai ukuran-ukuran tertentu. Untuk masingmasing regu, lapangan di bagi dua sama besar oleh net atau tali yang di bentangkan di atas lapangan dengan ukuran ketinggian ter tentu. Satu orang tidak boleh memantulkan bola dua kali secara berturutturut dan satu regu dapat memainkan bola maksimal tiga kali sentuhan di lapangan sendiri dan berusaha menjatuhkan bola di lapangan lawan atau mematikan bola di pihak lawan. Permainan di mulai dengan pukulan servis dari daerah servis. Peraturan dasar yang di gunakan adalah bola harus di pantulkan tangan, lengan, atau bagian depan badan dan anggota badan. Bola harus di sebrangkan ke lapangan lawan melalui atas net. Keterampilan permaianan bolavoli teknik dasar yaitu: servis, passing, umpan, smash, bendungan, dan receve. 
Olahraga prestasi adalah kegiatan olahraga yang dilakukan dan dikelola secara profesional dengan tujuan untuk memperoleh prestasi optimal pada cabangcabang olahraga. Atlet yang menekuni salah satu cabang tertentu untuk meraih prestasi, dari mulai tingkat daerah, nasional, serta internasional, mempunyai syarat memiliki tingkat kebugaran dan harus memiliki keterampilan pada salah satu cabang olahraga yang ditekuninya tentunya diatas rata-rata non atle.Seperti yang tercantum pada (UU Nomber 3 Tahun 2005 Tentang Sistem Keolahragaan Nasional) Olahraga Prestasi adalah olahraga yang membina dan mengembangkan olahragawan secara terencana, berjengjang, dan berkelanjutan melalui kompetisi untuk mencapai prestasi dengan dukungan ilmu pengetahuan dan teknologi keolragaan. Olahraga prestasi dapat dicapai dengan persiapan yang matang dan memerlukan proses yang baik.

Faktor teknik dasar dalam olahraga juga bisa jadi pengaruh terhadap suatu keberhasilan untuk mencapai prestasi, teknik dasar yang dimaksud adalah teknik dasar permainan bolavoli khususnya di teknik smash karena teknik dasar smashmerupakan salah satu teknik dasar serangan dalam permaiana bolavoli yang dilakukan di atas dekat atau jauh dari net. Adapun rangkaian gerakan smash yang kompleks, yaitu: langkah persiapan atau awalan, Tolakan atau lompatan, memukul bola saat melayang di udara dan mendarat.

Olahraga prestasi adalahkegiatan olahraga yang dilakukan dan dikelola secara profesional dengan tujuan untuk memperoleh prestasi optimal pada cabangcabang olahraga. Atlet yang menekuni salah satu cabang tertentu untuk meraih prestasi, dari mulai tingkat daerah, nasional, serta internasional, mempunyai syarat memiliki tingkat kebugaran dan harus memiliki keterampilan pada salah satu cabang olahraga yang ditekuninya tentunya diatas rata-rata non atle, sedankan dalam penelitian ini yang diteliti olahraga permain bolavoli. Pemecahan masalah prestasi olahraga khususnya bolavoli harus ditinjau dari ilmu pengetahuan agar mencapai sasaran tertentu yaitu pencapaian prestasi. Dalam usaha pencapaian prestasi maksimal sebenarnya ada beberapa faktor Pencapaian prestasi olahraga yaitu aspek fisik, aspek teknik, aspek taktik, aspek mental. Faktor fisik yaitu yang berkaitan dengan struktur, postur dan kemampuan motorik yang ditentukan secara genetik merupakan salah satu faktor penentu prestasi yang terdiri dari beberapa komponen dasar yaitu:kekuatan (strength), kecepatan (speed), kelentukan (flexibility), kelincahan(agility), daya tahan (endurance), daya ledak (explosive power), keseimbangan(balance), koordinasi (coordination) Kemampuan motorik manusia yangkomplek ini dapat 
ditingkatkan sesuai dengan kekhususan cabang olahragamasing-masing.

Pemain bolavoli yang baik diperlukan dukungan kemampuan fisik yang baik.Misalnya dalam teknik dasar smashmerupakan salah satu teknik dasar serangan dalam permaiana bolavoli yang dilakukan di atas dekat atau jauh net. yang mempunyai rangkaian garak yang kompleks, yaitu: langkah persiapan atau awalan, Tolakan atau lompatan, memukul bola saat melayang di udara dan mendarat. Pencapaian prestasi olahraga bolavoli yang optimal diperlukan latihan-latihan yang benar, kontinyu dan teratur serta pemecahan masalah prestasiolahraga yang baik pula. Hal ini disebabkan apabila dalam latihan kurang benar, dan tidak direncanakan terlebih dahulu maka jalannya latihan kurang sempurna dan prestasi olahraga bolavoli tidak maksimal.

Berdasarkan observasi dan pengamatan pada tanggal 03 sampai dengan 26 April 2016 permasalahan dalam penelitian ini bahwapada ekstrakurikuler bolavoli putra di SMA Negeri 1 Luragung merupakan salah satu sekolah yang mengikuti kompetisi antar sekolah tingkat SMA/MA/SMK di Semua pemainnya merupakan anggota pelajar SMA Negeri 1 Luragung. Tempat yang digunakan untuk berlatih adalah lapangan SMANegeri 1 Luragung. Sebelum diadakan penelitian, peneliti mengamati langsung dilapangan. Para pemain bolavoli Ekstrakurikuler bolavoli putra di SMANegeri 1 Luragung mempunyai kemampuan yang berbeda-beda antara pemain satu dengan pemain yang lainnya, yaitu mengenai kemampuan tolakan di bagian teknik dasar smash masih rendah. Hal ini terlihat pada saat latihan maupun pertandingan ada pemain yang memiliki kemampuan tolakan masih rendah, ada juga pemain yang memiliki kemampuan tolakan yang tinggi. Apablia di rata-ratakan hasil kemampuan tolakan pada teknik dasar smash bolavoli para pemain Ekstrakurikuler bolavoli putra di SMA Negeri 1 Luragung memiliki kemampuan tolakan masih rendah. Padahal untuk mencapai sebuah pukulan yang maksimal sehingga pukulan dapat di arahkan ke sasaran lapangan lawan itu bisa terarah, maka teknik dasarsmash bolavoli dibutuhkan kemampuan tolakan yang tinggi. Para pemain Ekstrakurikuler bolavoli putra di SMANegeri 1 Luragung dalam permainan belum dapat memaksimalkan dan memanfaatkan Kemampuan tolakan yang tinggi dalam teknik dasarsmash, padahal fungsi kemampuan tolakan dalam teknik dasar smashsangat besarmanfaatnya, karena salah satu aspek yang menunjang keberhasilan untuk mencapai sebuah pukulan yang maksimal sehingga pukulan dapat di arahkan ke sasaran lapangan lawan yang kosong itu dan terarah, maka teknik dasa smash bolavoli dibutuhkan kemampuan tolakan yang tinggi. 
Salah satu pencapaian prestasi olahraga bolavoli memerlukan berbagai pertimbangan,perhitungan dan analisis yang cermat mengenai faktor-faktor yang menunjangprestasi bolavoli yang telah disebutkan di atas. Faktor-faktor penentu dan penunjang keberhasilan smashtersebut dapat dijadikan dasar dalam menyusun programlatihan. Salah satu progaram latihan. Chu (1992:1) bahwa plyometric adalah "latihan yang dilakukan dengan sengaja untuk meningkatkan kemampuan atlet, yang merupakan perpaduan latihan kecepatan dan kekuatan. Perpaduan antara kecepatan dan kekuatan merupakan perwujudan dari daya ledak otot".

Mengingat pentingnya peranan latihan didalam meningkatkan prestasi, untuk itu akan diteliti mengenai "Pengaruh Latihan PlyometricTerhadap Hasil Smash Dalam Permainan Bolavoli Pada Ekstrakurikuler Bolavoli Putra di SMANegeri 1 Luragung".

\section{METODE}

Metode dalam penelitian ini adalah kuantitatif jadi kuantitatif sering dinamakan metode tradisional, metode kuantitatif sering dinamakan sebagai metode baru, karena metode ini sudah cukup lama digunakan metode ini disebut metode kuantitatif karena data penelitian berupa angka-angka dan analisis menggunakan statistik menurut Sugiyono (2015:13).

Metode penelitian adalah cara yang digunakan oleh peneliti dalammengumpulkan data penelitiannya. Sedangkan menurut Sugiyono (2015:3) penelitian adalah merupakan cara ilmiah untuk mendapatkan data dengan tujuandan kegunaan tertentu. Berdasarkan pengertian tersebut terdapat empat hal yangperlu dipahami lebih lanjut yaitu: cara ilmiah, data, tujuan dan kegunaan.Penelitian itu merupakan cara ilmiah, berarti penelitian itu didasarkan padaciri-ciri keilmuan yaitu: rasional, empiris dan sistematis. Menurut sugiyono (2015:107) "mengatakan metode penelitian eksperimen dapat diartikan sebagai metode penelitian yang digunakan untuk mencari pengaruh perlakuan tertentu terhadap yang lain dalam kondisi yang terkendalikan".

Metode penelitian yang digunakan dalam penelitian ini adalah metode preeksperimental yang menurut Arikunto (2013:123) mengatakan "sering dipandang sebagai eksperimen tidak sebenarnya" di sebut demikian karena eksperimen jenis ini belum memenuhi persyaratan seperti eksperimen yang dikatakan ilmiah mengikuti peraturan-peraturan tertentu. Metode ini digunakan atas dasar pertimbangan bahwa sifat penelitian preeksperimental yaitu mencobakan sesuatu untuk mengetahui pengaruh atau akibat dari suatu perlakuan atau treatment.

Untuk mempermudah langkahlangkah yang harus dilakukan dalam penelitian, diperlukan desain yang dijadikan pegangan agar penelitian tidak keluar dari 
ketentuan yang sudah ditetapkan, sehingga tujuan atau hasil yang diinginkan akan sesuai dengan harapan. Dalam rangka mencapai tujuan tersebut, penulis dalam penelitian ini, menggunakan eksperimen design menurut Arikunto (2013:124) yaitu Pretest-Posttest Grup Design.

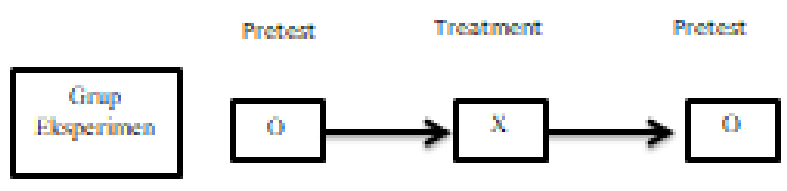

Gambar 1 Rancangan Penelitian

\section{HASIL PENELITIAN}

Tes awal dan akhir (pre test post test) adalah tes yang dilaksanakan sebelum dan sesudah diberikan perlakuan. Tes yang digunakan adalah keterampilan smash yaitu tes yang di lakukan dengan cara testee berada dalam daerah serang atau bebas di lapangan permainan, bola dilambungkan atau di umpan dekat atas jaring ke arah testee, dengan atau tanpa awalan, testee meloncat dan memukul bola melampaui atas jaring ke dalam lapangan di seberangnya dimana terdapat sasaran dengan angka-angka, stopwatch dijalankan pada waktu bola tersentuh oleh tangan testee, dan di hentikan pada saat bola menyentuh lantai, tes ini di lakukan 5 kali pengulangan.

Hasil pretest yang dilakukan pada awal latihan dapat dijadikan alat ukur untuk mengetahui keterampilan smash dalam permainan bolavoli pada ekstrakulikuler bolavoli putra di SMA Negeri 1 Luragung. Dari hasil pengolahan data tes awal mengetahui keterampilan smash dalam permainan bolavoli, hasil data pre test memiliki kemampuan awal yang masih rendah dalam keterampilan smash dalam permainan bolavoli. hasil dari Pre test (tes awal) dengan tes smash dari sebelum di berikan treatmet dan kemudian setelah selesai dilakukan, maka didapatkan hasil sebagai berikut : pre test diperoleh jumlah nilai 850 nilai rata-rata 50, simpangan baku 7,29, nilai tertinggi 63,69 dan nilai terendah adalah 39,56. Hasil post test yang dilakukan pada akhirlatihan dapat dijadikan alat ukur untuk mengetahui keterampilan smash dalam permainan bolavoli pada ekstrakulikuler bolavoli putra di SMA Negeri 1 Luragung hasil.

Dari hasil pengolahan data tes akhir keterampilan smash dalam permainan bolavoli, hasil data dengan memiliki kemampuan akhir yang meningkatdalam keterampilan smash dalam permainan bolavoli. Hasil posttestketerampilan smash dalam permainan bolavoli pada 
keterampilan smash dalam permainan bolavoli pada ekstrakulikuler bolavoli putra di SMA Negeri 1 Luragung hasil data post test setelah latihan plyometricmemperoleh nilaihasil jumlah nilai 981,33, nilai rata-rata 57, simpangan baku 7,3516232, nilai tertinggi 67,28, dan nilai terendah 43,79.

1. Analisis Uji Normalitas Data

Salah satu persyaratan dalam analisis kuantitatif adalah terpenuhinya asumsi kenormalan terhadap distribusi data yang akan dianalisis uji perbedaan rata-rata dari prê test dan post test terlebih dahulu dilakukan uji normalitas terhadap data pre test dan post test yang telah dikumpulkan. Hasil dari perhitungan data pre test di dapat post test di dapat $\mathrm{L}_{\text {hitung }} 0,077$. dengan $\mathrm{n} 17$ dan taraf nyata 0,05 , dari daptar tabel yang di lampirkan di dapat $\mathrm{L}_{\text {tabel }} 0,206$ yang lebih basar dari post test ( $\mathrm{L}_{\text {hitung }}<\mathrm{L}_{\text {tabel }}$ ) maka dari $\mathrm{L}_{\text {hitung }}$ dapat disimpulkan berdistribusi "normal".

2. Analisis uji homogenitas

Hasil perhitungan uji homogenitas dengan menentukan nilai hitung pre testdan post testketerampilan smash dalam permainan bolavoli pada keterampilan smash dalam permainan bolavoli pada ekstrakulikuler bolavoli putra di SMA Negeri 1 Luragung hasil data pre testdan post testsebelum dan sesudah latihan plyometric. Menentukan nilai $\mathrm{F}$ dari tabel dengan taraf nyata 0,01 akan dicari $\mathrm{F}_{0.05}$ (16/16) sebagai berikut: $\mathrm{F}_{\text {tabel }}: \mathrm{F}_{0.05(16 / 16)}=$
$2,33 \quad \mathrm{~F}_{\text {hitung }}<\mathrm{F}_{\text {tabel }}=1,17<2,33$. Dengan demikian kedua varian homogen.

3. Pengujian hipotsis

Apakah Terdapat PengaruhLatihan Plyometric Terhadap Hasil Smash Dalam Permainan Bolavoli Pada Ekstrakurikuler Bolavoli Putra Di SMA Negeri 1 Luragung? Untuk mengetahui pengaruhlatihan selanjutnya dilakukan uji hipotesis dan hasilnya menunjukkan bahwa terdapat pengaruh latihan plyometric tehadap hasil smash dalam permainan bolavoli pada ekstrakurikuler bolavoli putra di SMA Negeri 1 Luragung pada taraf kepercayaan $(\alpha) 0,05$. dengan penghitungan dari uji statistik data pre test dan post test hasil tes smash pada peserta ekstrakurikuler bola voli putra dengan uji $t$.Untuk melihat deskriptif persentasi data uji t. Dari perhitungan kedua data pre test dan post test yang di dapat $\mathrm{t}_{\text {hitung }} 3,89$ dan dengan $\mathrm{n}$ 17 dan taraf nyata 0,05 , dari daftar tabel yang di lampirkan di dapat $t_{\text {tabel }} 2,11$. Jika dibandingkan, dapat dilihat nilai $\mathrm{t}$ hitung $(3,89>2,11) \mathrm{t}_{\text {tabel }}$ maka $H_{O}$ ditolak. Dengan ditolaknya $H_{O}$ disimpulkan bahwa terdapat pengaruh latihan plyometric terhadap hasil smash pada ekstrakurikuler bolavoli putra di SMA Negeri 1 Luragung.

4. Hasil peningkatan antara pre test dan post test

Hasil peningkatan jumlah nilai akhir antara pretestdan posttest keterampilan smash dalam permainan bolavoli pada ekstrakurikuler bolavoli putra di SMA 
Negeri 1 Luragung hasil pre testdan posttest sebelum dan sesudah latihan plyometric.Adapun hasil peningkatan dari pre test dan post testdengan tes smash dari sebelum dan sesudah di berikantreantatmet dan kemudian setelah selesai dilakukan, maka didapatkan hasil sebagai berikut : pre test diperoleh jumlah nilai akhir 850,00, post testdiperoleh jumlah akhir 998,97, hasil dari peningkatan pre test dan post test 0,85 , hasil dari peningkatan\%pre test dan post test $85,08 \%$.

Berdasarkan hasil pengolahan data pengaruh latihan plyometric terhadap hasil smash dalam permainan bolavoli pada ekstrakurikuler bolavoli putra di SMA Negeri 1 Luragung. Maka penulis menarik kesimpulan sebagai berikut:Hipotesis Terdapat Pengaruh Latihan Plyometric Terhadap Hasil Smash Dalam Permainan Bolavoli Pada Ekstrakurikuler Bolavoli Putra Di SMA Negeri 1 Luragung. Mengapa latihanplyometricberpengaruh terhadap hasil smash karena merupakan metode yang paling efektif untuk mengembangkan kemampuan explosive power.

Ketika otot ditarik, itu mengembangkan kekuatan elastis. Ini bukan proses metabolisme, itu adalah murni fisik. Latihan plyometric adalah salah satu bentuk latihan yang sangat baik untuk membantu meningkatkan eksplosip power. Bahkan bisa menjadi latihan yang bermanfaat untuk meningkatkan tolakan tertinggi dalam gerak dasar smash karena dalam teknik dasar smash tolakan tertinggi sangat dibutuhkan agar mengarahkan sebuah pukulan bisa terarahkan dengan baik.

Hal diatas di buktikan berdasarkan dari hasil statistik uji $t$ Dari perhitungan kedua data pre test dan post test yang di dapat $\mathrm{t}_{\text {hitung }} 3,89$ dan dengan $\mathrm{n} 17$ dan taraf nyata 0,05 , dari daftar tabel yang di lampirkan di dapat $\mathrm{t}$ tabel 2,11. Jika dibandingkan, dapat dilihat nilai $\mathrm{t}$ hitung $(3,89>2,11) \mathrm{t}$ tabel maka $H_{O}$ ditolak. Dengan ditolaknya $H_{O}$ disimpulkan bahwa terdapat pengaruh latihan plyometric terhadap hasil smash pada ekstrakurikuler bolavoli putra di SMA Negeri 1 Luragung.

\section{SIMPULAN}

Berdasarkan hasil pengolahan data pengaruh latihan plyometric terhadap hasil smash dalam permainan bolavoli pada ekstrakurikuler bolavoli putra di SMA Negeri 1 Luragung. Maka penulis menarik kesimpulan sebagai berikut:“Terdapat Pengaruh Latihan Plyometric Terhadap Hasil Smash Dalam Permainan Bolavoli Pada Ekstrakurikuler Bolavoli Putra Di SMA Negeri 1 Luragung".

\section{DAFTAR PUSTAKA}

Adhri .2010. pendidikan olahraga dan kesehatan di sekolah dasar. Jakarta : Pustaka Setia

Ali Maksum .2012. Metode Penelitian Dalam Olahraga. Surabaya : Unesa University Press 
Amung Mamun .2001. Pendekatan

Keterampilan Taktis Dalam

Pembelajaran Bolavoli. Depertemen

Pendidikan Nasional Direktorat

Jenderal Pendidikan Dasar Dan

Menengah.

Anung .2013. "Pengaruh Latihan

Plyometric"Hurdle Hopping" dan

"Depth Jumps" terhadap loncatan

Atlet Bolavoli Pervas Seleman.

Universitas Negeri Semarang

Arikunto .2013. Prosedur Penelitian (Satu

Pendekatan Praktik). Jakarta: PT

Rineka Cipta.

Dieter Beutelstalhl .2013. Belajar Bermain

Bola Voli. Bandung : CV Pionir Jaya

Feri Kurniawan .2013. Buku Pintar Pengetahuan Olahraga.Jakarta: PT. Laskar Aksara.

Harsono .1988.Coaching Dan Aspek-Aspek Psikologi Dalam Coaching. Jakarta: $\mathrm{RJ} \times \mathrm{xi}$

Heriyanto .2011. "Pengaruh Latihan Squat Jump Terhadap Akurasi Smash

Dalam Permainan Bolavoli Pada Siswa Kelas VII SMP Negri 1 Mandirancan Kabupaten Kuningan. Universitas Majalengka.

Husdarta .2011. Manajemen Pendidikan Jasmani. Bandung : Alfabeta

Irfan Rizka Zaniari .2011. "Pengaruh Latihan Plyometric dan Standing Jump Terhadap Teknik Hand spring
Pada Atlet Senam Artistik Persani Gunung Kidul". Universitas Negeri Semarang.

Mardiana .2009. Pendidikan Jasmani Dan Olahraga. Bandung alfabeta.

Nurhasan .2001. Tes Dan Pengukuran Dalam Pendidikan Jasmani (Perinsip-Perinsip Dan Penrapanya). Jakarta: Direktorat Jendral Olahraga, Depdiknas.

Nuril Ahmadi .2007.Panduan Olahraga Bolavoli. Solo:Era Pustaka Utama.

Sajoto .2005. Peningkatan Dan Pembinaan Kekuatan Kondisi Fisik Dalam Olahraga. Semarang : PT prize

Sudjana .2013.Metoda Statistika. Bandung : PT. Tarsito Bandung

Sugiyono .2015. Metode Penelitian Pendidikan (Pendekatan Kuantitatif Kualitatif). Bandung: Alfabeta.

Suharno.2005. Ilmu Kepelatihan Olahraga. Yogyakarta: PT. Kristus

Suherman .2007. Jasmani Olahraga Dan Kesehatan. Depok : CV ARYA DUTA

Sukadiyanto .2002. Pengantar Teori Dan Metodologi Melatih Fisik. Yogyakarta : POK FIK UNY

Toto Subroto .2010. Modul Permainan Bolavoli. Bandung : Fakultas Pendidikan Olahraga Dan Kesehatan UPI 